\title{
Revenue Malmquist Productivity Index And Application In Bank Branch
}

\author{
M. Navanbakhsh \\ Department of Sociology, Science \& Research Branch \\ Islamic Azad University, Tehran, Iran \\ G. R. Jahanshahloo \\ Department of Mathematical Teacher Traveling University, Tehran, Iran \\ F. Hossienzadeh Lotfi $^{1}$ and Z.Taeb \\ Department of Mathematics, Science \& Research Branch \\ Islamic Azad University, Tehran, Iran
}

Keywords: Data envelopment analysis, Malmquist productivity index, Revenue efficiency, Cost efficiency.

\section{INTRODUCTION}

Productivity growth is one of the major sources of economic development. In recent years the owners and analysis of productivity have had several scientific developments in firm and industry performances. These studies have been focused on data gathering of productivity and their experiences. This has been resulted better efficiency and providing useful information for owners and designers of public and private sectors.In the last, only efficiency change was used for progress and regress studies [1], but it has been shown that the technical change has effects in productivity, too. Hereof MPI was determined [2]. Fare et al. (1992, 1994a) developed MPI, which was suggested initially by Malmquist (1953) [3]. He assimilated Fare's views for efficiency measurements and Caves et al. (1983) recommendations for productivity evaluation; and defined MPI for each unit based on inputs disposal and outputs products [4, 5]. Hereafter many researches were completed for calculation of this index and several applications were procured $[6,7]$. Cost Malmquist productivity index was reported, where instead technical efficiency, the cost efficiency for every unit was prevented. This index is useful when the costs and the demand of any unit's input and the value of the output are available [8]. In this paper, the

\footnotetext{
${ }^{1}$ Corresponding Auther, TEL: +98-21-44804172-4, P.O.Box 14155-775
} 
1234 F. Hosseinzadeh Lotfi, G. R. Jahanshahloo, M. Navanbakhsh and Z. Taeb

Revenue Malmquist productivity index is used. This index could be calculated when the price of each outputs is available and progress and regress of output revenue is the basis. At first section, basic definitions of Data Envelopment Analysis will be illustrated $[9,10,11]$, then in section three, the definitions of MPI, and in section four RM are presented. In the last section for commercials Bank is used and the obtained data are reported and discussed.

\section{Data Envelopment Analysis}

For each manager, information regarding unit's efficiency is one of the important factors to measure the productivity using efficiency of units, because productivity of each system is a function of efficiency and impression. Before eighteenth century several researches have been investigated to measure the efficiency in a system. Here a system means a set from which Decision Making Units (DMU) will be chosen and a DMU could be efficient, when that unit procures the best benefits from the existing facilities of unit.

The amount of obtained DMUs is hypothesized in a system as $\mathrm{n}$ and $D M U_{j}$, $j=1, \ldots, n$ is the $j^{\text {th }}$ Decision Making Unit. This DMU includes $m$ inputs $X_{j}=\left(x_{i j}, \ldots, x_{m j}\right)$ and $s$ outputs $Y_{j}=\left(y_{i j}, \ldots, y_{s j}\right)$. The inputs and outputs of each DMU are non-negative and at least one of the inputs and outputs are positive. Production possibility set $T_{c}$ is procured from non-empty, possibility, constant return to scale, and convexity is:

$$
T_{c}=\left\{(X, Y) / X \geq \sum_{j=1}^{n} \lambda_{j} X_{j}, Y \leq \sum_{j=1}^{n} \lambda_{j} Y_{j}, \lambda_{j} \geq 0, j=1, \ldots, n\right\}
$$

This set is named as production possibility set of CCR model. Frontier of $T_{c}$ that is a piecewise linear surface, is named efficiency frontier. Each DMU on this frontier is relative efficiency; and the others are inefficiency. If $D M U_{o}$ dose not place on frontier (inefficiencies ones), could be transferred with difference methods to the frontier. One of these methods is CCR model, with the definition of the input oriented as below:

$$
\text { Min } \quad \theta \text { s.t. } \quad \sum_{j=1}^{n} \lambda_{j} X_{j} \leq \theta X_{o} \quad \sum_{j=1}^{n} \lambda_{j} Y_{j} \geq Y_{o} \quad \lambda_{j} \geq 0, \quad j=1, \ldots, n
$$

The unknowns of above problem are $\theta, \lambda_{1}, \ldots, \lambda_{n}$. With the definition: $\theta$ is the value of relative efficiency of $D M U_{o}$.

\section{Malmquist Productivity Index}

Farell (1957) determined a suitable method to evaluate experimental production function for several inputs and outputs with using linear programming technique and Data Envelopment Analyses (DEA). By applying DEA, the best efficiency frontier will be calculated with a set of DMUs and omitting of any priority for inputs and outputs. The DMUs of efficiency frontier are the units 
with the maximum output and/or the minimum input levels. Using the efficient units and efficiency frontier, is the analysis of other inefficiency units possible. Malmquist Productivity Index is defined with assimilation efficiency changes of each unit and technology changes. MPI can be calculated via several functions, such as distance function:

$$
D\left(X_{o}, Y_{o}\right)=\inf \left\{\theta /\left(\theta X_{o}, Y_{o}\right) \in P P S\right\}
$$

This equation shows in special conditions, only the efficiency frontier change at time $t+1$ related to $t$; that could not be a suitable criterion to calculate the technology change. If $D^{k}\left(X^{k}, Y^{k}\right)=1$, then $k^{t h}$ unit is hypothesized as efficient. This distance function dose not defines the inefficiency values. Fare decomposed MPI into two components, using linear inefficiency of technology frontier. The efficiency frontier will be specified for each DMU with DEA. Production function is tant $t$ and $t+1$. Calculation of the MPI requires four linear programming problems as below: $O \in Q=\{1,2, \ldots, n\}$

$$
\begin{aligned}
& D_{o}^{t}\left(X_{o}^{t}, Y_{o}^{t}\right)=\operatorname{Min} \quad \theta \\
& \text { s.t. } \quad \sum_{j=1}^{n} \lambda_{j} x_{i j}^{t} \leq \theta x_{i o}^{t}, \quad i=1, \ldots, m \\
& \sum_{j=1}^{n} \lambda_{j} y_{r j}^{t} \geq y_{r o}^{t}, \quad r=1, \ldots, s \\
& \lambda_{j} \geq 0, \quad j=1, \ldots, n
\end{aligned}
$$

$x_{i o}^{t}$ is the $i^{t h}$ input and $y_{r o}^{t}$ is the $r^{t h}$ output of $D M U_{o}$ at time $t$. The value of efficiency $\left(D_{o}^{\prime}\left(X_{o}^{t}, Y_{o}^{t}\right)=\theta_{o}^{*}\right)$ shows that how much can be decrease inputs of $D M U_{o}$ to production that output.

Instead $t$, CCR problem (4), is calculated at time $t+1$ and is equal $D^{t+1}\left(X_{o}^{t+1}, Y_{o}^{t+1}\right)$ and is the technical efficiency for $D M U_{o}$ at time $t+1$. The value of $D^{t}\left(X_{o}^{t+1}, Y_{o}^{t+1}\right)$ for $D M U_{o}$, is the distance of $D M U_{o}$ at $t+1$ with the frontier of time $t$, calculated by below problem:

$$
\begin{aligned}
& D^{t}\left(X_{o}^{t+1}, Y_{o}^{t+1}\right)=\operatorname{Min} \quad \theta \\
& \text { s.t. } \quad \sum_{j=1}^{n} \lambda_{j} x_{i j}^{t} \leq \theta x_{i o}^{t+1}, \quad i=1, \ldots, m \\
& \sum_{j=1}^{n} \lambda_{j} y_{r j}^{t} \geq y_{\text {ro }}^{t+1}, \quad r=1, \ldots, s \\
& \lambda_{j} \geq 0, \quad j=1, \ldots, n
\end{aligned}
$$


1236 F. Hosseinzadeh Lotfi, G. R. Jahanshahloo, M. Navanbakhsh and Z. Taeb

$$
\begin{aligned}
D^{t+1}\left(X_{o}^{t}, Y_{o}^{t}\right)=\operatorname{Min} & \theta \\
\text { s.t. } & \sum_{j=1}^{n} \lambda_{j} x_{i j}^{t+1} \leq \theta x_{i o}^{t}, \quad i=1, \ldots, m \\
& \sum_{j=1}^{n} \lambda_{j} y_{r j}^{t+1} \geq y_{r o}^{t}, \quad r=1, \ldots, s \\
& \lambda_{j} \geq 0, \quad j=1, \ldots, n
\end{aligned}
$$

The same model $D^{t+1}\left(X_{o}^{t}, Y_{o}^{t}\right)$ is calculated.

Fare hypotheses $D_{o}^{t+1}\left(X_{o}^{t+1}, Y_{o}^{t+1}\right), D_{o}^{t}\left(X_{o}^{t}, Y_{o}^{t}\right)$ must be equal to 1 to be efficient. Therefore he defined relative efficiency change as:

$$
T E C_{o}=\frac{D_{o}^{t+1}\left(X_{o}^{t+1}, Y_{o}^{t+1}\right)}{D_{o}^{t}\left(X_{o}^{t}, Y_{o}^{t}\right)}
$$

He described one geometric compotation to determine technology change between $t$ and $t+1$ :

$$
F S_{o}=\left[\frac{D_{o}^{t}\left(X_{o}^{t+1}, Y_{o}^{t+1}\right)}{D_{o}^{t+1}\left(X_{o}^{t+1} Y_{o}^{t+1}\right)} \cdot \frac{D_{o}^{t}\left(X_{o}^{t}, Y_{o}^{t}\right)}{D_{o}^{t+1}\left(X_{o}^{t}, Y_{o}^{t}\right)}\right]^{\frac{1}{2}}
$$

MPI will be calculated from multiplication efficiency change and technology change for each input oriented $D M U_{o}$ at time $t$ and $t+1$ :

$$
M_{o}=\frac{D_{o}^{t+1}\left(X_{o}^{t+1}, Y_{o}^{t+1}\right)}{D_{o}^{t}\left(X_{o}^{t}, Y_{o}^{t}\right)}\left[\frac{D_{o}^{t}\left(X_{o}^{t+1}, Y_{o}^{t+1}\right)}{D_{o}^{t+1}\left(X_{o}^{t+1} Y_{o}^{t+1}\right)} \cdot \frac{D_{o}^{t}\left(X_{o}^{t}, Y_{o}^{t}\right)}{D_{o}^{t+1}\left(X_{o}^{t}, Y_{o}^{t}\right)}\right]^{\frac{1}{2}}
$$

The simple form of relation (9) is:

$$
M_{o}=\left[\frac{D_{o}^{t}\left(X_{o}^{t+1}, Y_{o}^{t+1}\right)}{D_{o}^{t}\left(X_{o}^{t} Y_{o}^{t}\right)} \cdot \frac{D_{o}^{t+1}\left(X_{o}^{t+1}, Y_{o}^{t+1}\right)}{D_{o}^{t+1}\left(X_{o}^{t}, Y_{o}^{t}\right)}\right]^{\frac{1}{2}}
$$

This value defines geometric convex compotation, because it specified the smallest decrease of efficiencies and any small change in each efficiency effects in MPI. Three conditions are available:

1. $M_{o}>1$, Increase productivity and observe progress.

2. $M_{o}<1$, Decrease productivity and observe regress.

3. $M_{o}=1$, No change in productivity at time $t+1$ in comparison to $t$.

\section{Revenue Malmquist Productivity Index}

Pursuant to previous section, RM is an index for signification progress and regress each unit based on consideration benefit as product $Y^{t}$. This section discusses revenue frontier change and reverie efficiency using MPI, as described 
4.1. Assumed. At time period $t$, product output $Y^{t} \in \mathbb{R}^{\sim}$ with dispose of each input unit $X^{t} \in \mathbb{R}^{\gg}$. The production technology at time $t$ is defined as output offer set witch is

$$
L^{t}\left(X^{t}\right)=\left\{Y^{t} \mid Y^{t} \text { can product } X^{t}\right\}
$$

$L^{t}\left(X^{t}\right)$ contains all output vectors, which can be produced from $X^{t}$. This set is non-empty, closed, convex, bounded, and satisfies strong disposability of inputs and outputs. Bound of the set is named as output isoquant, that is:

$$
\text { IsoqL } L^{t}\left(X^{t}\right)=\left\{Y^{t} ; Y^{t} \in L^{t}\left(X^{t}\right), \lambda Y^{t} \notin L^{t}\left(X^{t}\right) \text { for } \lambda>1\right\}
$$

This set shows a boundary (frontier) to the output offer set in the sense that any radial expansion of output vectors that lie on the frontier is not possible within $\operatorname{Lt}(\mathrm{Xt})$. The output distance function is defined as:

$$
D_{o}^{t}\left(X^{t}, Y^{t}\right)=\sup \left\{\varphi \mid\left(\varphi Y^{t}\right) \in L^{t}\left(X^{t}\right), \varphi>o\right\}
$$

The subscript $o$ denotes output orientation. $D_{o}^{t}\left(X^{t}, Y^{t}\right)$ in (13) is the highest possible demand, which can be multiplied whit $Y^{t}$ remains in $L^{t}\left(X^{t}\right)$. If $D_{o}^{t}\left(X^{t}, Y^{t}\right)>1$, then $Y^{t} \in \operatorname{int} L^{t}\left(X^{t}\right)$. If $D_{o}^{t}\left(X^{t}, Y^{t}\right)=1$, then $Y^{t} \in$ $I \operatorname{soq} L^{t}\left(X^{t}\right)$. $D_{o}^{t}\left(X^{t}, Y^{t}\right)$ is similar with the definition of technical efficiency in output oriented:

$$
T E_{o}^{t}\left(X^{t}, Y^{t}\right)=\operatorname{Max}\left\{\varphi \mid\left(\varphi Y^{t}\right) \in L^{t}\left(X^{t}\right), \varphi>o\right\}
$$

When output price $W^{t} \in \mathbb{R}^{\sim}$, are available, the revenue function is defined:

$$
R^{t}\left(X^{t}, W^{t}\right)=\operatorname{Max}\left\{W^{t} Y^{t} \mid Y^{t} \in L^{t}\left(X^{t}\right), W^{t}>o\right\}
$$

$R^{t}\left(X^{t}, W^{t}\right)$ is the maximum revenue of producing outputs $Y^{t}$. Frontier of this set is:

$$
\operatorname{Isoq} R^{t}\left(X^{t}, W^{t}\right)=\left\{Y^{t} \mid W^{t} Y^{t}=R^{t}\left(X^{t}, W^{t}\right)\right\}
$$

This boundary contains the output vectors that can have the maximum revenue with their price $W^{t}$. Therefore technical efficiency and distance function have the same definition. Overall efficiency defines:

$$
O E_{o}^{t}\left(X^{t}, Y^{t}, W^{t}\right)=\frac{W^{t} Y^{t}}{R^{t}\left(X^{t}, W^{t}\right)}
$$

Because technical efficiency is less than overall efficiency (revenue) for each unit, then:

$$
T E_{o}^{t}\left(X^{t}, Y^{t}\right) \leq O E_{o}^{t}\left(X^{t}, Y^{t}, W^{t}\right)
$$

According to technical efficiency is the same as distance function:

$$
D_{o}^{t}\left(X^{t}, Y^{t}\right) \leq \frac{W^{t} Y^{t}}{R^{t}\left(X^{t}, W^{t}\right)}
$$

Allocative efficiency defines as follows:

$$
A E_{o}^{t}\left(X^{t}, Y^{t}, W^{t}\right)=\frac{W^{t} Y^{t}}{D_{o}^{t}\left(X^{t}, Y^{t}\right) R^{t}\left(X^{t}, W^{t}\right)}
$$


1238 F. Hosseinzadeh Lotfi, G. R. Jahanshahloo, M. Navanbakhsh and Z. Taeb

Malmquist productivity index [3] with distance function is defined:

$$
\begin{aligned}
O M^{t} & =\left[\frac{D_{o}^{t}\left(X^{t}, Y^{t}\right)}{D_{o}^{t}\left(X^{t+1}, Y^{t+1}\right)}\right] \\
O M^{t+1} & =\left[\frac{D_{o}^{t+1}\left(X^{t}, Y^{t}\right)}{D_{o}^{t+1}\left(X^{t+1}, Y^{t+1}\right)}\right]
\end{aligned}
$$

$O M^{t}$ compose DMUs at time $t$ and $t+1$ to frontier $t$. $O M^{t+1}$ compose DMUs at time $t$ and $t+1$ to frontier $t+1$. Malmquist productivity index (OM) is a geometric component of (21) and (22):

$$
O M=\left[\frac{D_{o}^{t}\left(X^{t}, Y^{t}\right)}{D_{o}^{t}\left(X^{t+1}, Y^{t+1}\right)} \cdot \frac{D_{o}^{t+1}\left(X^{t}, Y^{t}\right)}{\left.D_{o}^{t+1}, Y_{o}^{t+1}\right)}\right]^{\frac{1}{2}}
$$

$\mathrm{OM}$ is Malmquist productivity index and has inverse relative with $M_{o}$ definition pervious section. Three conditions are exited:

1. $O M>1$, observe progress.

2. $O M<1$, observe regress.

3. $O M=1$, do not observe any change in productivity.

4.2. Revenue Malmquist Productivity Index. By using Allocative and technical efficiency, output's price productivity changes are determined. To take care of (21) to (23) Revenue Malmquist Productivity Index (RM) is calculated as:

$$
\begin{aligned}
R M^{t} & =\left[\frac{W^{t} Y^{t} / R^{t}\left(X^{t}, W^{t}\right)}{W^{t} Y^{t+1} / R^{t}\left(X^{t+1}, W^{t}\right)}\right] \\
R M^{t+1} & =\left[\frac{W^{t+1} Y^{t} / R^{t+1}\left(X^{t}, W^{t}\right)}{W^{t+1} Y^{t+1} / R^{t+1}\left(X^{t+1}, W^{t+1}\right)}\right] \\
R M & =\left[\frac{W^{t} Y^{t} / R^{t}\left(X^{t}, W^{t}\right)}{W^{t} Y^{t+1} / R^{t}\left(X^{t+1}, W^{t}\right)} \cdot \frac{W^{t+1} Y^{t} / R^{t+1}\left(X^{t}, W^{t+1}\right)}{W^{t+1} Y^{t+1} / R^{t+1}\left(X^{t+1}, W^{t+1}\right)}\right]
\end{aligned}
$$

And $W^{t} Y^{t}=\sum_{n=1}^{N} w_{n}^{t} y_{n}^{t}, n$ is the $n^{t h}$ output and $R^{t}\left(X^{t}, W^{t}\right)$ is the maximum reverie which is calculated in (15). OM index discusses outputs quantity and RM index discusses outputs reverie. $\frac{W^{t} Y^{t}}{R^{t}\left(X^{t}, W^{t}\right)}$ is the reverie efficiency to product $Y^{t}$ at time period $t$ with output price $W^{t}$. This fraction compares reverie of output $Y^{t}$ and the maximum product reverie and its value is not less than 1. Value 1 means this output has the maximum reverie and value greater than one means this output can be decreased. This fraction is exactly overall efficiency as defined in (17). Therefore with using overall efficiency and OM, RM can be provided. RM is the value that shows which output's part can increase arrive reverie frontier. (Using constant return to scale is not necessary, but it is only for clear and distinction bench mark of reverie frontier).

Similarity OM index, for RM can say:

1. $R M>1$, observe progress and decrease productivity. 
2. $R M<1$, observe regress and increase productivity.

3. $R M=1$, no change in productivity.

In next section RM decomposed to compare this index and its application.

4.3. Decomposition of Revenue Malmquist Productivity Index. RM index mentioned in (26) can be decomposed easily in to OM index mentioned in (23). Results of this composition are overall efficiency change (OEC) and revenue technical change (RTC). Each of these components can be self decomposed as follow:

4.3.1. First stage of decomposition. As said before, RM index can be decomposed into OEC and RTC:

$$
\begin{aligned}
R M= & \frac{W^{t} Y^{t} / R^{t}\left(X^{t}, W^{t}\right)}{W^{t+1} Y^{t+1} / R^{t+1}\left(X^{t+1}, W^{t+1}\right)} \\
& {\left[\frac{W^{t+1} Y^{t+1} / R^{t+1}\left(X^{t+1}, W^{t+1}\right)}{W^{t} Y^{t+1} / R^{t}\left(X^{t+1}, W^{t}\right)} \cdot \frac{W^{t+1} Y^{t} / R^{t+1}\left(X^{t}, W^{t+1}\right)}{W^{t} Y^{t} / R^{t}\left(X^{t}, W^{t}\right)}\right]^{\frac{1}{2}} }
\end{aligned}
$$

in (27) the numerator and denominator of the component outside the square brackets are the value of overall efficiency change at two time periods $t$ and $t+1$, that is OEC; and it value indicates whether the production unit catches up the revenue boundary when going from period $t$ to period $t+1$ or not. The component inside the square brackets indicates RTC, which is reverie frontier change. RTC compares product revenue for each output to the maximum product.

4.3.2. Second stage of decomposition. Here the first component of decomposition can be decomposed again:

The composition of OEC: It can be decomposed into technical efficiency change (TEC) and allocative efficiency change (AEC):

$$
O E C=\frac{D_{o}^{t}\left(X^{t}, W^{t}\right)}{D_{o}^{t+1}\left(X^{t+1}, W^{t+1}\right)} \times \frac{W^{t} Y^{t} /\left[R^{t}\left(X^{t}, W^{t}\right) \cdot D_{o}^{t}\left(X^{t}, W^{t}\right)\right]}{W^{t+1} Y^{t+1} /\left[R^{t+1}\left(X^{t+1}, W^{t+1}\right) \cdot D_{o}^{t+1}\left(X^{t+1}, W^{t+1}\right)\right]}
$$

The first component on the right side of (28) indicates technical change. The second component in (28) is allocative efficiency change.

The decomposition of RTC: this component can be decomposed as follow:

$$
\begin{aligned}
& R T C=\left[\frac{D_{o}^{t+1}\left(X^{t+1}, Y^{t+1}\right)}{D_{o}^{t}\left(X^{t+1}, Y^{t+1}\right)} \cdot \frac{D^{t+1}\left(X^{t}, Y^{t}\right)}{D^{t}\left(X^{t}, Y^{t}\right)}\right]^{\frac{1}{2}} \\
& {\left[\frac{W^{t+1} Y^{t+1} /\left[R^{t+1}\left(X^{t+1}, W^{t+1}\right) D_{o}^{t+1}\left(X^{t+1}, Y^{t+1}\right)\right]}{W^{t} Y^{t+1} /\left[R^{t}\left(X^{t+1}, W^{t}\right) D_{o}^{t}\left(X^{t+1}, Y^{t+1}\right)\right]} \frac{W^{t+1} Y^{t} /\left[R^{t+1}\left(X^{t}, W^{t+1}\right) D_{o}^{t+1}\left(X^{t}, Y^{t}\right)\right]}{W^{t} Y^{t} /\left[R^{t}\left(X^{t}, W^{t}\right) D_{o}^{t}\left(X^{t}, Y^{t}\right)\right]}\right]^{\frac{1}{2}}}
\end{aligned}
$$

The first fraction on the right side indicates measure of technical change, which is one of the OM,s component. The second part in (29) is ratio of output's price change to the maximum revenue change, which represents (RE). The 
1240 F. Hosseinzadeh Lotfi, G. R. Jahanshahloo, M. Navanbakhsh and Z. Taeb

decomposition of RM can be summarized as:

$\mathrm{RM}=$ overall efficiency change $(\mathrm{OEC}) \times$ revenue technical change $(\mathrm{RTC})$

$=$ technical efficiency change $(\mathrm{TEC}) \times$ allocative efficiency change $(\mathrm{AEC})$ $\times$ revenue effect $(\mathrm{RE})$

$=\mathrm{OM} \times$ allocative efficiency change $(\mathrm{AEC}) \times$ revenue effect $(\mathrm{RE})$

4.4. Calculation of RM index and its components. Output distance function and revenue distance function are used to calculate allocative and technical efficiency. These components' calculation is by non-parametric programming and DEA technical possible of $\left(x_{o i}, y_{o r}\right)$ is calculated by follow model: The unit $\left(x_{o i}^{\prime}, y_{o r}^{\prime}\right)$ indicates $i^{\text {th }}$ input and $r^{\text {th }}$ output of unit $o^{\text {th }}$ at time period $t$. Product revenue at time $t$ for $r^{t h}$ component is $W^{t} Y^{t}$ and is calculated by $W^{t} Y^{t}=\sum_{r=1}^{s} w_{o r}^{t} y_{o r}^{t}$. Therefore the revenues $W^{t} Y^{t+1}, W^{t+1} Y^{t}, W^{t+1} Y^{t+1}$ are calculated with $\sum_{r=1}^{s} w_{o r}^{t} y_{o r}^{t+1}, \sum_{r=1}^{s} w_{o r}^{t+1} y_{o r}^{t+1}, \sum_{r=1}^{s} w_{o r}^{t+1} y_{o r}^{t+1}$. The value of $R^{t}\left(X^{t}, W^{t}\right)$ is calculated by follow model:

$$
\begin{array}{rlr}
R^{t}\left(X^{t}, W^{t}\right)=\operatorname{Max} & w_{o r}^{t} y_{r} & \\
\text { s.t. } & \sum_{j=1}^{n} z_{j} y_{j r}^{t} \geq y_{r}, & r=1, \ldots, s \\
& \sum_{j=1}^{n} z_{j} x_{i j}^{t} \leq x_{i k}^{t}, & i=1, \ldots, m \\
& z_{j} \geq 0, & j=1, \ldots, n \\
& y_{r} \geq 0, & \\
& & \\
R^{t}\left(X^{t+1}, W^{t}\right)=1, \ldots, s & \\
\text { s.t. } & \sum_{j=1}^{t} y_{r} z_{j} y_{j r}^{t} \geq y_{r}, & \\
& & \\
& \sum_{j=1}^{n} z_{j} x_{i j}^{t} \leq x_{i k}^{t+1}, & i=1, \ldots, s \\
& z_{j} \geq 0, y_{j} \geq 0, & j=1, \ldots, n
\end{array}
$$

changing $t$ to $t+1$ and converse. The distance functions are calculated: The values of $R_{o}^{t+1}\left(X^{t+1}, Y^{t+1}\right)$ and $R_{o}^{t+1}\left(X^{t}, Y^{t}\right)$ could be available with the same models as (30) and (31) by

$$
\begin{aligned}
& D_{o}^{t}\left(X^{t}, W^{t}\right)=\operatorname{Max} \quad \theta \\
& \text { s.t. } \quad \sum_{j=1}^{n} z_{j} y_{j r}^{t} \geq y_{k r}^{t}, \quad r=1, \ldots, s \\
& \sum_{j=1}^{n} z_{j} x_{i j}^{t} \leq \theta x_{i k}^{t}, \quad i=1, \ldots, m \\
& z_{j} \geq 0, \quad j=1, \ldots, n
\end{aligned}
$$




$$
\begin{aligned}
& D_{o}^{t}\left(X^{t+1}, W^{t}\right)=\operatorname{Max} \quad \theta \\
& \text { s.t. } \quad \sum_{j=1}^{n} z_{j} y_{j r}^{t} \geq y_{k r}^{t+1}, \quad r=1, \ldots, s \\
& \sum_{j=1}^{n} z_{j} x_{i j}^{t} \leq \theta x_{i k}^{t+1}, \quad i=1, \ldots, m \\
& z_{j} \geq 0, \quad j=1, \ldots, n
\end{aligned}
$$

The values $D_{o}^{t+1}\left(X^{t+1}, Y^{t+1}\right)$ and $D_{o}^{t+1}\left(X^{t}, Y^{t}\right)$ are calculated, too, with the same model. By using of the above models, the RM index is calculated. This is a criterion to appointment revenue progress and regress of a system. This index is important for owners and public designers, because it discusses the revenue of product.

\section{Application of Revenue Malmquist Productivity Index}

In this section, Cost Malmquist productivity and revenue Malmquist productivity indexes will be studied from application view and the results of this consideration will be reported in form of tables.

5.1. Data. By using GAMS programming for 36 branches of Iranian commercial bank branches will be calculate Cost and Revenue Malmquist productivity index. Each unit has 3 inputs and 5 outputs as follow:

\begin{tabular}{|l|l|}
\hline Inputs & Outputs \\
\hline 1. Payable interest & 1. Public deposits \\
2. Personnel & 2. Non-Public deposits \\
3. Non performing loans & 3. Loans granted \\
& 4. Received interest \\
& 5. Fee \\
\hline
\end{tabular}

Table 1. Inputs and Outputs Indexes

\section{Input indexes:}

1. Payable interested (I1): It means the advantage that the bank pay to each customer and it is some of payable interest of payable interest of branches.

2. Personnel (I2): It means the total of the personnel who are working in each branch.

3. Non performing loans (I3): It is an index that creates when the customers don not pay their loans; summarize the non performing loans is the branch's none performing loans.

\section{Output indexes:}

1. Public deposits (O1): It is the total of four main deposits.

2. Non-Public deposits (O2): It is outer deposits which not note in 1 .

3. Loans granted facilities (O3): It is any loans in a branch. All of them are loans granted (facilities) in a branch.

4. Received interest (O4): It is the advantage of loans granted facilities that 
1242 F. Hosseinzadeh Lotfi, G. R. Jahanshahloo, M. Navanbakhsh and Z. Taeb customers pay.

5. Fee (O5): It received when the branch does services to customer.

5.2. Results analysis. Each table the first, calculated efficiency value at time period $t$; and indicates efficiency changes and technical changes; in the end, determined Malmquist productivity index.

If efficiency change and technical change are greater than 1, then instance indexes is greater than 1 and observe progress; if two of them are less than 1 instance index are less than 1 and observe regress; otherwise if deficit in one of change amends with another change instance unit is progress. In table 5 notice that unit 1 has efficiency change and technical change greater than 1 , therefore $R M>1$, and this unit has reverie progress. Unit 10 has efficiency change less than 1 and technical change amends deficit, and $R M>1$, observe progress. necessary equal 1 for efficiency. Because of efficiency is calculated for each unit at a time to another time's frontier it can be greater than 1and it is not Finally, observe that whit using this index, progress and regress appointment will be carefully and applicatory. 
Revenue Malmquist Productivity Index And Application...

\begin{tabular}{|c|c|c|c|c|c|c|c|c|}
\hline & I1 & $\mathrm{I} 2$ & I3 & O1 & $\overline{\mathrm{O} 2}$ & O3 & $\mathrm{O} 4$ & $\mathrm{O} 5$ \\
\hline 1 & 1475.26 & 36.54 & 42810 & 2578287 & 356990 & 1627013 & 1360.72 & 439.73 \\
\hline 2 & 2019.26 & 174.81 & 38840 & 917241 & 32086 & 590739 & 3826.03 & 524.65 \\
\hline 3 & 11234.43 & 481.76 & 265915 & 5194917 & 451694 & 4226854 & 65005.41 & 5231.33 \\
\hline 4 & 9959.5 & 508.21 & 301871 & 4586566 & 983999 & 3668742 & 11100.86 & 1213.14 \\
\hline 5 & 3463.2 & 349.41 & 83723 & 1966426 & 454031 & 2727931 & 35486.25 & 3149.79 \\
\hline 6 & 9078.58 & 278.44 & 500984 & 3664338 & 261773 & 55921 & 156717.53 & 1848.33 \\
\hline 7 & 9522.39 & 397 & 82883 & 5269974 & 312655 & 2735519 & 28452.94 & 2649.24 \\
\hline 8 & 4077.01 & 479.98 & 496950 & 4319584 & 1308445 & 13324914 & 29406.31 & 5182.72 \\
\hline 9 & 2104.19 & 262.13 & 88015 & 1024665 & 63040 & 909081 & 4434.86 & 967.78 \\
\hline 10 & 782.31 & 151.19 & 26641 & 565345 & 13220 & 156617 & 769.94 & 221.83 \\
\hline 11 & 9921.01 & 750.58 & 51310 & 3506837 & 142287 & 1089604 & 11119.47 & 1469.9 \\
\hline 12 & 3715.97 & 544.43 & 56717 & 1373245 & 42309 & 815105 & 25161.37 & 595.39 \\
\hline 13 & 58.04 & 30.81 & 2227 & 86446 & 17204 & 15454 & 549.63 & 41.8 \\
\hline 14 & 1831.06 & 181.94 & 18793 & 525142 & 19520 & 241729 & 1678.56 & 261.32 \\
\hline 15 & 982.85 & 192.96 & 20917 & 489549 & 22567 & 310081 & 2086.39 & 402.61 \\
\hline 16 & 7016.04 & 697.99 & 106258 & 2692686 & 128459 & 1667839 & 10924.76 & 2064.82 \\
\hline 17 & 565.15 & 135.95 & 26461 & 374585 & 13912 & 282274 & 3943.99 & 744.73 \\
\hline 18 & 80.73 & 49.2 & 18978 & 231898 & 5214 & 264384 & 1272.41 & 222.48 \\
\hline 19 & 4522.28 & 429.17 & 130562 & 1610813 & 115385 & 968329 & 9964.54 & 2517.26 \\
\hline 20 & 700.75 & 108.45 & 22675 & 346601 & 35473 & 3592 & 983429.27 & 457.37 \\
\hline 21 & 599.92 & 151.85 & 24970 & 464746 & 29676 & 355414 & 3202.48 & 1101.66 \\
\hline 22 & 987.86 & 150.26 & 38363 & 434916 & 14105 & 385666 & 3711.41 & 418.93 \\
\hline 23 & 1997.14 & 428.61 & 46734 & 1080937 & 27965 & 639256 & 6120.45 & 1162.14 \\
\hline 24 & 1691.12 & 469.31 & 78889 & 1440176 & 104670 & 1037745 & 15024.42 & 2121.56 \\
\hline 25 & 351.75 & 135.64 & 26076 & 366844 & 8483 & 253671 & 2831.38 & 557.09 \\
\hline 26 & 843.14 & 62.66 & 16393 & 177381 & 5361 & 262289 & 4014.31 & 305.49 \\
\hline 27 & 437.24 & 125.9 & 22622 & 383170 & 7881 & 311718 & 3644.57 & 375.74 \\
\hline 28 & 525.38 & 115.6 & 10337 & 458151 & 13203 & 322065 & 3311.05 & 573.73 \\
\hline 29 & 421.89 & 169.42 & 33478 & 391168 & 17299 & 241369 & 2274.11 & 1014.67 \\
\hline 30 & 1149.08 & 251.94 & 36926 & 916901 & 35075 & 646924 & 5899.33 & 885.41 \\
\hline 31 & 1271.39 & 307.1 & 40706 & 786031 & 21968 & 678959 & 6434.53 & 978.82 \\
\hline 32 & 8009.31 & 1099.03 & 355928 & 2622893 & 123394 & 2211448 & 19493.28 & 3411.81 \\
\hline 33 & 1008.11 & 176.05 & 17896 & 592656 & 20038 & 987688 & 6522.43 & 1227.74 \\
\hline 34 & 1262.37 & 154.26 & 18094 & 425496 & 12783 & 217203 & 1605.9 & 624.52 \\
\hline 35 & 1039.59 & 214.56 & 25915 & 576971 & 15551 & 565672 & 3586.5 & 483.98 \\
\hline 36 & 5376.56 & 527.31 & 7942 & 1315223 & 48781 & 1071052 & 9185.96 & 1143.34 \\
\hline
\end{tabular}

Table 2. Inputs and outputs value, at time $t$ 
1244 F. Hosseinzadeh Lotfi, G. R. Jahanshahloo, M. Navanbakhsh and Z. Taeb

\begin{tabular}{|c|c|c|c|c|c|c|c|c|}
\hline & I1 & $\mathrm{I} 2$ & I3 & $\mathrm{O} 1$ & $\mathrm{O} 2$ & O3 & $\mathrm{O} 4$ & $\mathrm{O} 5$ \\
\hline 1 & 1475.26 & 36.95 & $\overline{22222}$ & 2290697 & 426262 & 1712520 & 100502.95 & 439.73 \\
\hline 2 & 2019.26 & 9.14 & 57375 & 3001 & 46912 & 564804 & 78316.56 & 524.65 \\
\hline 3 & 11234.43 & 485.78 & 270980 & 5242723 & 600403 & 4279961 & 352119.81 & 5231.33 \\
\hline 4 & 9959.5 & 524.01 & 11676 & 4682582 & 757950 & 3836221 & 1040739.02 & 1213.14 \\
\hline 5 & 3463.2 & 355.05 & 153 & 1946292 & 553593 & 2604435 & 213686.99 & 3149.79 \\
\hline 6 & 9078.58 & 281.27 & 523793 & 618610 & 38201 & 5731482 & 1308473.46 & 1848.33 \\
\hline 7 & 9522.39 & 404.9 & 82692 & 5347169 & 375537 & 2822805 & 24663 & 52649.24 \\
\hline 8 & 4077.01 & 477.86 & 513554 & 4231800 & 12088 & 13816384 & 546829.47 & 5182.72 \\
\hline 9 & 2104.19 & 265.41 & 89268 & 1027275 & 86315 & 944054 & 11344 & 967.78 \\
\hline 10 & 2.31 & 150.29 & 061 & 9 & 15814 & 154 & 214 & 221.83 \\
\hline 11 & 9921.01 & 761.17 & 479 & 59316 & 169549 & 1114642 & 169056.57 & 1469.9 \\
\hline 12 & 3715.97 & 553.84 & 56541 & 74064 & 48452 & 827562 & 119583.77 & 595.39 \\
\hline 13 & .04 & .46 & 43 & & 175 & 162 & 4.13 & 41.8 \\
\hline 14 & 18 & 18 & 18 & 3093 & 29096 & 243607 & 26645.94 & 261.32 \\
\hline 15 & 2.85 & 7 & 366 & 12 & 24973 & 321492 & 37246.46 & 402.61 \\
\hline 16 & 7016.04 & 8.43 & 107364 & 2700652 & 180729 & 1683119 & 327533.83 & 2064.82 \\
\hline 17 & 565.15 & 7.66 & 985 & 86 & 15042 & 90 & 527 & 744.73 \\
\hline 18 & .73 & .72 & 218 & 5 & 7242 & 268058 & 39370.76 & 222.48 \\
\hline 19 & 4522.28 & 5.86 & 9588 & 1635426 & 115347 & 1004498 & 162240.29 & 2517.26 \\
\hline 20 & 0.75 & 10 & 599 & & & 14 & 590 & 457.37 \\
\hline 21 & 9.92 & .07 & 1910 & 462702 & 30393 & & 4357 & 1101.66 \\
\hline 22 & & & & & 184 & 112 & 816 & 418.93 \\
\hline 23 & 19 & & & 43 & 33964 & & .26 & 1162.14 \\
\hline 24 & 1691.12 & .94 & 0381 & & 63 & & 1072619 & 135881.08 \\
\hline 25 & & & & & 11525 & & 4204 & 557.09 \\
\hline 26 & & .45 & & & 8137 & 263 & 5282 & 305.49 \\
\hline 27 & 7.24 & & 535 & 356899 & 7270 & 324076 & 63086.67 & 375.74 \\
\hline 28 & 5.38 & 5.74 & 471 & 466911 & 17487 & 332502 & 68716.39 & 573.73 \\
\hline $2 !$ & & & & & 21278 & & 42365.46 & 1014.67 \\
\hline 30 & 11 & & & 908 & 47018 & 695 & 113375.87 & 885.41 \\
\hline 31 & 1271.39 & & & & 363878 & & 147125.75 & 978.82 \\
\hline 32 & 8009.31 & 1103.82 & 364590 & 2574296 & 143821 & 2278791 & 27217 & 9.81 \\
\hline 3 & 1008.11 & & & & 19286 & 1019763 & 161825.69 & 1227.74 \\
\hline 34 & 1262.37 & & & & 17241 & 222096 & 53780.6 & 624.52 \\
\hline 35 & 1039.59 & & 28591 & 559179 & 18171 & 570138 & 75184.17 & 483.98 \\
\hline 36 & 5376.56 & 534.13 & 10516 & 1314954 & 57840 & 1077250 & 157648.19 & 1143.34 \\
\hline
\end{tabular}

Table 3. Inputs and outputs value, at time $t$ 


\begin{tabular}{|c|c|c|c|c|c|c|c|}
\hline MALM & $D^{t}(t)$ & $D^{t+1}(t)$ & $\overline{D^{t}(t+1)}$ & $\overline{D^{t+1}(t+1)}$ & Effic. Prog. & Tech. Prog. & Malmquist Ind. \\
\hline 1 & 1 & 1.1498 & 2.9548 & 1 & 1 & 1.603 & 1.60304 \\
\hline 2 & 1 & 0.3706 & 0.4304 & 0.45 & 0.45 & 1.6064 & 0.72282 \\
\hline 3 & 1 & 1.0061 & 1.0132 & 1 & 1 & 1.0035 & 1.00352 \\
\hline 4 & 0.5175 & 0.3147 & 1.5125 & 1 & 1.9323 & 1.577 & 3.04725 \\
\hline 5 & 1 & 1.165 & 1.2159 & 1 & 1 & 1.0216 & 1.02163 \\
\hline 6 & 1 & 1.0087 & 1.0354 & 1 & 1 & 1.0132 & 1.01318 \\
\hline 7 & 1 & 0.8231 & 1.078 & 0.8481 & 0.8481 & 1.2427 & 1.05392 \\
\hline 8 & 1 & 1.0141 & 1.3492 & 1 & 1 & 1.1535 & 1.15348 \\
\hline 9 & 0.5442 & 0.4437 & 0.4916 & 0.5893 & 1.0829 & 1.0116 & 1.09543 \\
\hline 10 & 0.528 & 0.4584 & 0.4588 & 0.4493 & 0.851 & 1.0846 & 0.92291 \\
\hline 11 & 1 & 0.6051 & 0.872 & 0.611 & 0.611 & 1.5357 & 0.93838 \\
\hline 12 & 1 & 0.73 & 0.4545 & 0.4657 & 0.4657 & 1.1562 & 0.53846 \\
\hline 13 & 1 & 1.0519 & 1.1105 & 1 & 1 & 1.0275 & 1.02748 \\
\hline 14 & 0.4699 & 0.3257 & 0.4432 & 0.3393 & 0.7221 & 1.3727 & 0.99118 \\
\hline 15 & 0.6375 & 0.4496 & 0.4951 & 0.5497 & 0.8623 & 1.13 & 0.97444 \\
\hline 16 & 0.603 & 0.3979 & 0.5499 & 0.6937 & 1.1504 & 1.0961 & 1.26102 \\
\hline 17 & 1 & 0.8432 & 0.7935 & 1 & 1 & 0.97 & 0.97003 \\
\hline 18 & 1 & 1.0634 & 3.1402 & 1 & 1 & 1.7184 & 1.71839 \\
\hline 19 & 0.6362 & 0.6397 & 0.6365 & 0.6406 & 1.0071 & 0.994 & 1.00101 \\
\hline 20 & 0.6735 & 0.5733 & 0.638 & 0.8421 & 1.2504 & 0.9434 & 1.17961 \\
\hline 21 & 1 & 1.0103 & 1.0545 & 1 & 1 & 1.0216 & 1.02163 \\
\hline 22 & 0.4461 & 0.3754 & 0.5724 & 0.6865 & 1.5387 & 0.9955 & 1.53178 \\
\hline 23 & 0.6952 & 0.5376 & 0.5403 & 0.5932 & 0.8532 & 1.0854 & 0.92603 \\
\hline 24 & 0.9648 & 0.8081 & 0.8251 & 0.8327 & 0.8631 & 1.0877 & 0.93879 \\
\hline 25 & 0.9145 & 0.851 & 0.9324 & 0.9314 & 1.0185 & 1.0372 & 1.05632 \\
\hline 26 & 0.5928 & 0.5802 & 0.6564 & 0.7574 & 1.2777 & 0.941 & 1.20225 \\
\hline 27 & 0.7971 & 0.6678 & 0.9211 & 1 & 1.2546 & 1.0485 & 1.3154 \\
\hline 28 & 1 & 0.9889 & 1.0686 & 1 & 1 & 1.0395 & 1.03954 \\
\hline 29 & 1 & 0.9966 & 1.1707 & 1 & 1 & 1.0839 & 1.08387 \\
\hline 30 & 0.7514 & 0.6782 & 0.7936 & 0.7178 & 0.9553 & 1.1067 & 1.05732 \\
\hline 31 & 0.6727 & 0.6091 & 0.769 & 0.7789 & 1.1578 & 1.0443 & 1.20903 \\
\hline 32 & 0.3717 & 0.3729 & 0.382 & 0.39 & 1.0494 & 0.988 & 1.03683 \\
\hline 33 & 1 & 1.006 & 2.4363 & 1 & 1 & 1.5562 & 1.5562 \\
\hline 34 & 0.5825 & 0.5639 & 0.8132 & 0.6089 & 1.0453 & 1.1745 & 1.22768 \\
\hline 35 & 0.574 & 0.5139 & 0.8323 & 0.5145 & 0.8962 & 1.3443 & 1.2048 \\
\hline 36 & 1 & 1.3056 & 1.8916 & 1 & 1 & 1.2037 & 1.20368 \\
\hline
\end{tabular}

Table 4. Malmquist productivity 
1246 F. Hosseinzadeh Lotfi, G. R. Jahanshahloo, M. Navanbakhsh and Z. Taeb

\begin{tabular}{|c|c|c|c|c|c|c|c|}
\hline$\overline{\mathrm{RM}}$ & $D^{t}(t)$ & $D^{t+1}(t)$ & $D^{t}(t+1)$ & $D^{t+1}(t+1)$ & Effic. Prog. & Tech. Prog. & Rev. Malmq. Ind. \\
\hline 1 & 1 & 0.9228 & 2.1001 & 1 & 1 & 1.5085 & 1.50853 \\
\hline 2 & 0.4148 & 0.2464 & 0.3176 & 0.268 & 0.6462 & 1.4122 & 0.91255 \\
\hline 3 & 0.5048 & 0.3635 & 0.4921 & 0.3631 & 0.7194 & 1.3718 & 0.98692 \\
\hline 4 & 0.3336 & 0.2879 & 0.56 & 0.3797 & 1.138 & 1.3074 & 1.48787 \\
\hline 5 & 0.9177 & 0.6702 & 0.8384 & 0.6816 & 0.7427 & 1.2978 & 0.96388 \\
\hline 6 & 0.4439 & 0.398 & 0.4358 & 0.4049 & 0.9123 & 1.0955 & 0.99945 \\
\hline 7 & 1 & 0.4984 & 1.0185 & 0.5398 & 0.5398 & 1.9456 & 1.05027 \\
\hline 8 & 1 & 0.9511 & 1.0554 & 1 & 1 & 1.0534 & 1.05342 \\
\hline 9 & 0.3528 & 0.3056 & 0.3991 & 0.3537 & 1.0028 & 1.1412 & 1.14439 \\
\hline 10 & 0.332 & 0.2859 & 0.3482 & 0.3044 & 0.917 & 1.1523 & 1.05669 \\
\hline 11 & 0.9151 & 0.4179 & 0.6888 & 0.4578 & 0.5003 & 1.815 & 0.90809 \\
\hline 12 & 0.4628 & 0.2332 & 0.3152 & 0.2093 & 0.4521 & 1.7292 & 0.78183 \\
\hline 13 & 1 & 0.9052 & 0.9695 & 0.8769 & 0.8769 & 1.1052 & 0.96912 \\
\hline 14 & 0.41 & 0.1995 & 0.3612 & 0.2306 & 0.5624 & 1.7942 & 1.00909 \\
\hline 15 & 0.4595 & 0.3052 & 0.4261 & 0.3346 & 0.7283 & 1.3846 & 1.00837 \\
\hline 16 & 0.4708 & 0.2357 & 0.4715 & 0.2801 & 0.595 & 1.8337 & 1.09097 \\
\hline 17 & 0.6498 & 0.5752 & 0.6756 & 0.61 & 0.9387 & 1.1186 & 1.05003 \\
\hline 18 & 1 & 0.8746 & 1.1914 & 1 & 1 & 1.1671 & 1.16712 \\
\hline 19 & 0.3393 & 0.2848 & 0.379 & 0.3101 & 0.9138 & 1.2067 & 1.10269 \\
\hline 20 & 0.4792 & 0.4087 & 0.5081 & 0.4321 & 0.9016 & 1.1743 & 1.05874 \\
\hline 21 & 0.8498 & 0.7311 & 0.891 & 0.7668 & 0.9023 & 1.1622 & 1.04862 \\
\hline 22 & 0.3238 & 0.2762 & 0.3801 & 0.3242 & 1.001 & 1.1725 & 1.17364 \\
\hline 23 & 0.4958 & 0.3523 & 0.4617 & 0.3703 & 0.7469 & 1.3247 & 0.98947 \\
\hline 24 & 0.742 & 0.6397 & 0.7642 & 0.6587 & 0.8877 & 1.16 & 1.02981 \\
\hline 25 & 0.7328 & 0.6366 & 0.8237 & 0.7161 & 0.9772 & 1.1507 & 1.12448 \\
\hline 26 & 0.3682 & 0.2254 & 0.3618 & 0.2488 & 0.6757 & 1.5413 & 1.04143 \\
\hline 27 & 0.5913 & 0.5101 & 0.6561 & 0.5662 & 0.9576 & 1.1589 & 1.10947 \\
\hline 28 & 1 & 0.6436 & 0.9533 & 0.7383 & 0.7383 & 1.4165 & 1.04574 \\
\hline 29 & 0.8528 & 0.7416 & 0.9275 & 0.8062 & 0.9454 & 1.1502 & 1.08735 \\
\hline 30 & 0.5806 & 0.4968 & 0.6606 & 0.5632 & 0.97 & 1.1708 & 1.1357 \\
\hline 31 & 0.5125 & 0.4383 & 0.6138 & 0.5217 & 1.018 & 1.173 & 1.19403 \\
\hline 32 & 0.2637 & 0.2247 & 0.2806 & 0.2392 & 0.907 & 1.1734 & 1.0642 \\
\hline 33 & 1 & 0.6437 & 1.2403 & 0.7546 & 0.7546 & 1.598 & 1.20583 \\
\hline 34 & 0.4944 & 0.2605 & 0.624 & 0.3511 & 0.7101 & 1.8366 & 1.30424 \\
\hline 35 & 0.4647 & 0.3516 & 0.4847 & 0.3863 & 0.8313 & 1.2876 & 1.07045 \\
\hline 36 & 1 & 1.1482 & 1.0317 & 1 & 1 & 0.9479 & 0.94791 \\
\hline
\end{tabular}

Table 5. Reverie Malmquist productivity index 


\section{REFERENCES}

[1] Fare, R., Grosskopf, Norris M., Zhang, Z., 1994. Productivity growth, technical progress, and efficiency change in industrialized counties, American Economic Review 84, 66-83.

[2] Yao Chen, Agha Iqbal Ali, 2003, DEA Malmquist productivity measure: New insights with an application to computer industry, European Journal of Operational Research, 2003, (forth coming).

[3] Malmquist, S., 1953. Index numbers and indifference surfaces, Trabajos de Estadistica 4, 209-242.

[4] Robert M. Thrall, 2000. Measures in DEA with an Application to the Malmquist Index, Journal of Productinity Analysis, 13, 125-137.

[5] Rikard Althin, 2001. Measurement of Productivity Changes: Two Malmquist Index Approaches, Journal of Productinity Analysis, 160, 107-128

[6] Berg, S. A., Forsund, F. R., Jansen, E. S., 1992, Malmquist indices of productivity growth during the deregulation of Norwegian banking, 1980-89, Scandinavian journal of economics (supplement), 211-228.

[7] Bernard, A. B., Jones, C. I., 1996. Comparing apples to oranges: Productivity convergence and measurement across industries and countries, American Economic Review 86, 1216-1238.

[8] Nikolaos Maniadakis, Emmanuel Thanassoulis, 2003, A cost Malmquist productivity index. European journal of operational research, 2003, (forth coming).

[9] Charnes, A., Cooper, W. W., Huang, Z. M., Wei, Q. L., 1989. Cone ratio data envelopment analysis and multi-objective programming, International journal of systems science 20, 1099-1118.

[10] Charnes A., W. W. Cooper and E. Rhodse, 1978, measuring the efficiency of decision making units, European Journal of Operational Research 2, 429-444.

[11] Cooper, W. W., Park, K. S., Pastor, J. T., 1999. Ram: Arang adjusted measure of inefficiency for use with additive models, and relation to other models and measure in DEA, Journal of Productivity Analysis 11, 5-42. 